\title{
A Demonstration of High Temperature MED-TVC Desalination Technology in the Gulf Area
}

\author{
Younggeun Lee ${ }^{1}$, Osman Ahmed Hamed ${ }^{2, ~ *, ~ A m r ~ M o h a m m a d ~ M a h m o u d ~}{ }^{2}$, Khalid Bamardouf ${ }^{2}$, \\ Sultan Ahmed ${ }^{3}$, Byungsung Park ${ }^{2}$, Abdulaziz Suliman Al-Jamhan ${ }^{2}$ \\ ${ }^{1}$ Corporate R\&D Institute, Doosan Heavy Industries \& Construction Co., Ltd., Yongin-si, South Korea \\ ${ }^{2}$ Desalination Technologies Research Institute (DTRI), SWCC, Al Jubail, Saudi Arabia \\ ${ }^{3}$ Doosan Water R\&D Center, Al Khobar, Saudi Arabia
}

Email address:

OHamed@swcc.gov.sa (O. A. Hamed),oahamed@yahoo.com(O. A. Hamed)

${ }^{*}$ Corresponding author

\section{To cite this article:}

Younggeun Lee, Osman Ahmed Hamed, Amr Mohammad Mahmoud, Khalid Bamardouf, Sultan Ahmed, Byungsung Park, Abdulaziz Suliman Al-Jamhan. A Demonstration of High Temperature MED-TVC Desalination Technology in the Gulf Area. American Journal of Chemical Engineering. Vol. 7, No. 2, 2019, pp. 57-64. doi: 10.11648/j.ajche.20190702.11

Received: April 14, 2019; Accepted: May 23, 2019; Published: June 19, 2019

\begin{abstract}
This work focuses on a multiple effect desalination system with thermal vapor compressor (MED-TVC) operating at a top brine temperature (TBT) of $85^{\circ} \mathrm{C}$ which is significantly above the common operation temperatures of conventional MED-TVC systems, limited to a range below $70^{\circ} \mathrm{C}$ mainly due to scale risk. Such increase in TBT would enhance the production and system economics. A pilot plant installed at the Desalination Technologies Research Institute (DTRI) of the Saline Water Conversion Corporation (SWCC) in Jubail, Saudi Arabia was operated at the TBT of $85^{\circ} \mathrm{C}$ over a 5 -month test period. Visual inspection of tube bundles after the test, in conjunction with chemical scale analysis showed that scaling was limited to a soft thin film scale, which was easily removed by flushing with water, which confirmed a low fouling potential analyzed from operation data. Techno-economic analysis of the MED-TVC system operating at a TBT of $85^{\circ} \mathrm{C}$, indicated up to $34 \%$ reduction in steam consumption and up to $16 \%$ reduction in the levelized cost of water (LCOW), when compared with a MED-TVC unit operating at a conventional TBT of $65^{\circ} \mathrm{C}$. Accordingly, the high temperature MED-TVC systems operating at a TBT of $85^{\circ} \mathrm{C}$ can be considered as a financially competitive and technologically reliable desalination option for the Gulf area which has challenging seawater characteristics.
\end{abstract}

Keywords: MED-TVC, Top Brine Temperature (TBT), Scaling, Fouling Factor, Levelized Cost of Water (LCOW)

\section{Introduction}

Nowadays, the seawater reverse osmosis (SWRO) desalination technology is mainly applied to new desalination plants, because it is considered as a more energy-efficient and environment-friendly process, compared to thermal processes [1]. However, since this technology is very sensitive to seawater conditions (i.e., clay, metal inorganics, organics and algal blooms), its performance is directly influenced by membrane fouling, leading to an increase in the O\&M cost and a decrease in plant availability due to shutdowns [2]. Therefore, it requires additional pretreatment processes for reliable operation when it is constructed in challenging seawater condition [3].
Although most existing thermal desalination technologies have relatively high energy consumption when compared to SWRO desalination technology, those systems can be reliably operated under severe seawater conditions, while there is also a significant potential to reduce energy consumption of thermal desalination technologies [4]. AlMutaz describes the salient features of MED-TVC systems which makes it one of the most promising desalination technologies [5]. A MED-TVC system consumes a lower amount of electrical energy compared to the MSF technology and a conventional MED [6-9]. During the 1990s and early 2000s, MED-TVC systems were limited in unit capacities [10], but the 15 MIGD unit of the Yanbu Phase 2 plant in Saudi Arabia is an example of a modular 
evaporator concept which allows to build evaporators with any unit capacity considered as practical and economical [5].

A possible high performance ratio (PR) of the MED-TVC can result in considerable reduction of steam consumption for the same water production in a cogeneration configuration [11] and would be the preferred form of thermal desalination technology in concentrated solar power (CSP) assisted cogeneration [12]. A higher top brine temperature (TBT) increases the operation temperature range of a MED-TVC system, allowing to design MED evaporators with a larger number of effects, which results in the increased PR [5], but it increases the risk of fouling/scaling potential [8]. Calcium carbonate is a dominant form of scale in the operation range up to $85^{\circ} \mathrm{C}$ while magnesium sulfate deposition begins occurring beyond $85^{\circ} \mathrm{C}$ [13]. While in a MSF process a forced brine flow inside the heat exchanger tubes leads to relatively uniform concentrations of the brine exposed to the heat exchange surface area, the concentration of a falling film applied to the outside of the tube bundles in a MED-TVC system can vary in a wide range due to factors like uneven feed water distribution, uneven evaporation, blocked nozzles, and etc. Also, a MSF process includes a ball cleaning system to remove scales which are generated inside of tube during the operation, but a MED-TVC is physically difficult to remove scales which was formed outside of tube. For those reasons, MSF plants have been generally designed to be operated at higher TBT of $112^{\circ} \mathrm{C}$, while existing conventional MED-TVC plants have been designed with a TBT in the range of $65^{\circ} \mathrm{C}$ to prevent scale occurrence. An advanced MED-TVC technology with a TBT of $85^{\circ} \mathrm{C}$ has been successfully developed through analytic and experimental studies in Korea [14]. Such higher TBT would allow the plant design to have more number of effects and more utilization of steam produced in individual stages, leading to better steam consumptions and economics.

In this study validation of operation elevated MED TBT $\left(85^{\circ} \mathrm{C}\right.$ ) with gulf conditions ( up to $45 \mathrm{~g} / 1$ salinity) aiming to enhance the performance and economics of the existing MED, the challenge was to confirm the ability of antiscaling treatment to handle such operation conditions without scale participation, a MED-TVC pilot plant has been operated over a period of 5 months at a TBT of $85^{\circ} \mathrm{C}$ in Jubail, Saudi Arabia, by Saline Water Conversion Corporation (SWCC) - Desalination Technology Research Institute (DTRI) in cooperation with Doosan Heavy Industries \& Construction. The objectives of the pilot test were (1) to validate the stable operation at a TBT of $85^{\circ} \mathrm{C}$, (2) to assess the efficiency of a newly developed antiscalant for a TBT of $85^{\circ} \mathrm{C}$ under the seawater conditions in the Arabian Gulf, and finally (3) to evaluate the system performance and the resulting levelized cost of water (LCOW) of a MED-TVC operating at TBT of $85^{\circ} \mathrm{C}$ compared to conventional thermal desalination technologies.

\section{Materials and Methods}

\subsection{Demonstration Pilot Plant}

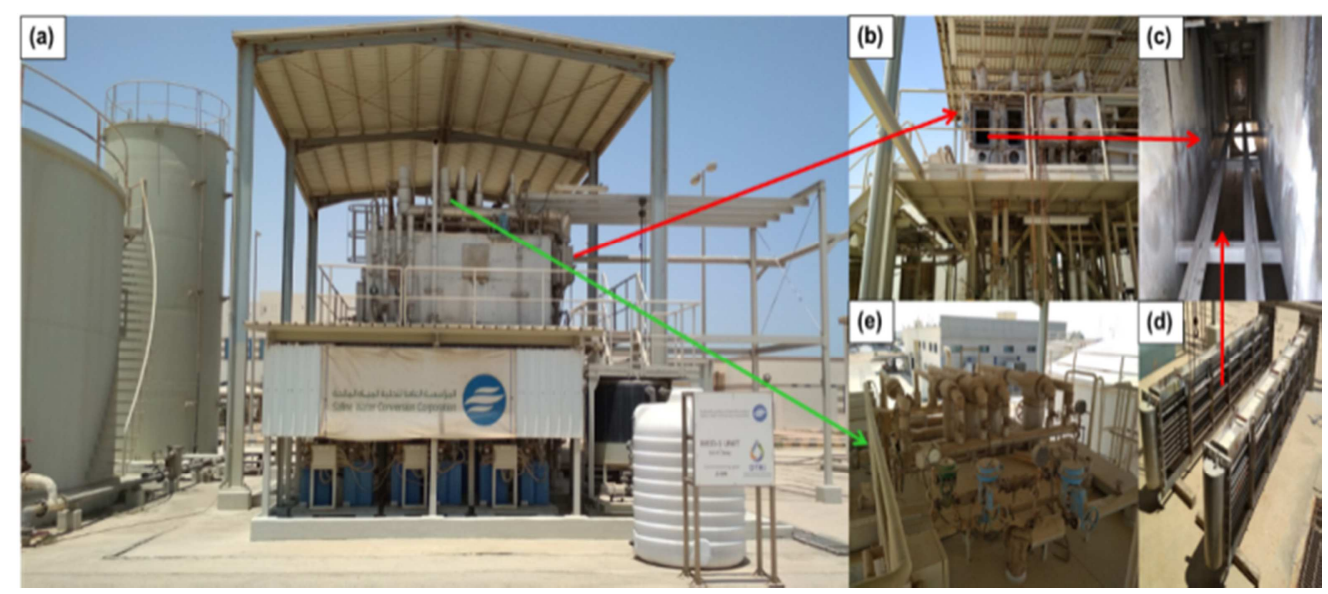

Figure 1. The MED-TVC pilot plant located in Jubail-Saudi Arabia.

The MED-TVC pilot plant shown in Figure 1 was utilized to explore the prospects of operating the unit at TBT of $85^{\circ} \mathrm{C}$. The pilot plant with a capacity of $1.0 \mathrm{~m}^{3} / \mathrm{h}$ comprises an evaporator with four effects. Feed water is distributed in parallel to all effects. In the effects, the feed water is distributed over the tube bundles by perforated plates as shown in Figure 1(d). The tube material is titanium (Ti) with an outside diameter of $18.88 \mathrm{~mm}$, a wall thickness of 0.70 $\mathrm{mm}$, and a length of $3.6 \mathrm{~m}$. As shown in Figure 2, the make- up seawater which is heated up by brine and distillate passing through plate type heat exchangers is mixed with concentrated brine to form recirculating brine with elevated TDS and temperature, which is used as the feed water in the effects. As vapor is condensing inside the tubes of the effect tube bundles, heat is transferred to the feed water falling film on the outside of the tubes, which results in a partial evaporation of the feed water. While each of the four effects operates at consecutive lower temperatures and pressures, the 
vapor released from the falling film in one effect passes as heating steam to the next effect where it condenses inside the tubes. The falling film reaches a maximum TDS of 65,000 ppm in each effect, which is the same TDS condition of brine in commercial MED plants. The distillate produced in each effect is moved from effect to effect and finally collected in the final condenser. A portion of vapor produced in the fourth effect is recompressed by the TVC and combined with the motive steam coming from the boiler, while the vapor mixture discharging from the TVC becomes the heating steam of the first effect. The remaining amount of vapor is condensed by cooling seawater in the final condenser. The effects are vented to remove non-condensable gases (NCG) to avoid a negative impact of NCG on the heat transfer coefficient (HTC). Specially, the HT-MED pilot plant was operated at a TBT of $85^{\circ} \mathrm{C}$ under the optimized liquid loading rate and antiscalant dosing rate, which were obtained based on the previous tests in Korea [14]. The optimized liquid loading rate $(\mathrm{kg} / \mathrm{s} / \mathrm{m}$ tube length) is the crucial factor of MED-TVC design to ensure a sufficient flow of feed on the tubes to avoid dry zones on the tube. Also, the minimized antiscalant dosing rate is essential to reduce operation cost of the plant while preventing scale formation.

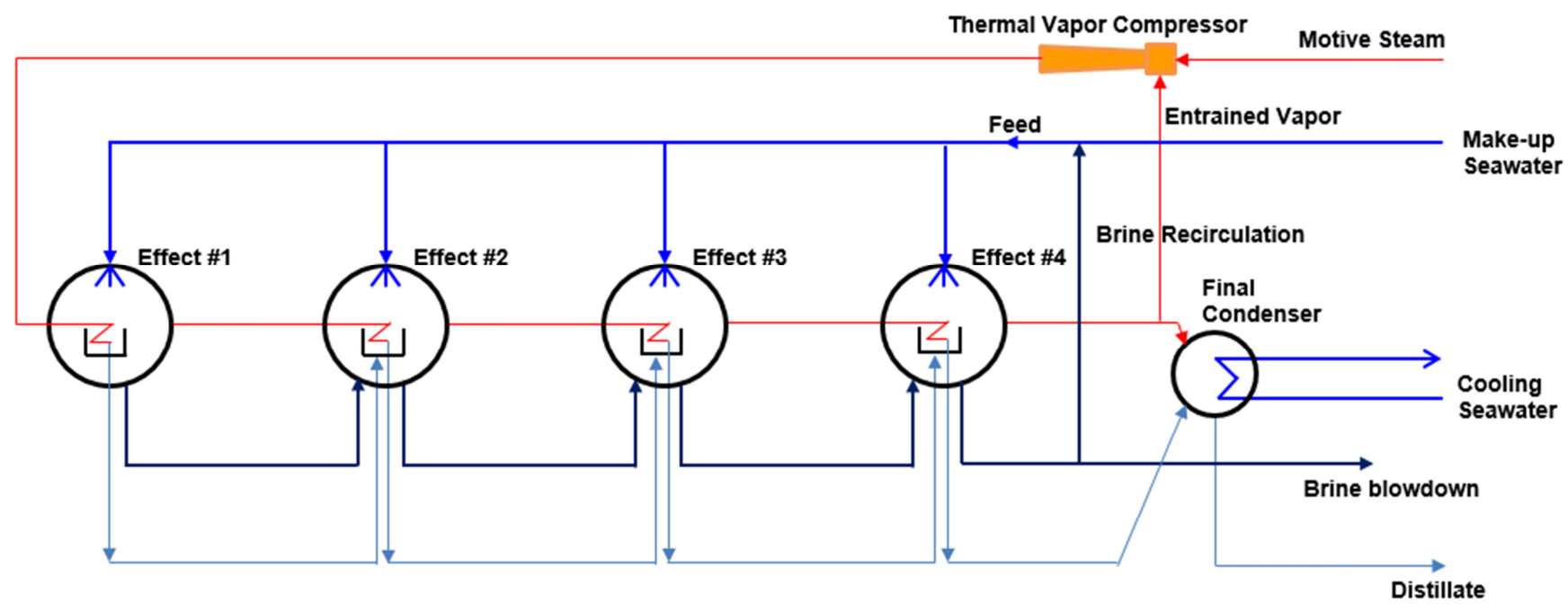

Figure 2. Schematic diagram of MED-TVC pilot plant.

\subsection{Thermal Performance Calculation}

The hourly measured data such as flow rate, temperature, pressure, and conductivity are collected over the 5-month operation period through a SCADA system installed at the MED-TVC pilot plant. The variables recorded in the SCADA system are: Mass flowrates of the following streams such as make-up seawater, feed in effects 1-4, brine recirculation, brine blowdown, distillate after final condenser, distillate to desuperheater, and motive steam; Temperatures of motive steam after desuperheater, vapor and condensate in effects 14, make-up seawater, feed, brine recirculation; Pressures of motive steam, motive steam before desuperheater, and vapor in effects 1-4; Conductivities of make-up seawater, brine, and total distillate, which are converted to total dissolved solids (TDS) using a conversion factor.

The performance of pilot plant depends on its ability to transfer heat from steam inside the tubes to the feed water falling film outside the tubes. Therefore, scale deposition on the outer surface of the tubes increases overall heat transfer resistance and fouling resistance, leading to the decrease of performance which can be estimated by the performance ratio (PR) as described in Eq. 1.

$$
\mathrm{PR}=\frac{\dot{m}_{\text {product water }}}{\dot{m}_{s, \text { motive }}} \times \frac{2,326 \mathrm{~kJ} / \mathrm{kg}}{\lambda_{s, \text { motive }}}
$$

where $\dot{\mathrm{m}}_{\text {product water }}=$ mass flowrate of product water $[\mathrm{kg} / \mathrm{hr}]$, $\dot{\mathrm{m}}_{\mathrm{s}, \text { motive }}=$ mass flowrate of motive steam $[\mathrm{kg} / \mathrm{hr}]$,

$\lambda_{\mathrm{s}, \text { motive }}=$ the latent heat of motive steam $[\mathrm{kJ} / \mathrm{kg}]$.

Each distillate flowrate was calculated by heat and mass balance equation to extract the amount of entrained vapor from effect 4 to the TVC. Since the methodology and formulas are almost identical in all effects, those for Effect 1 are representatively shown as follows:

$$
\begin{gathered}
Q_{\text {Total }, E 1}=\dot{m}_{s, E 1} \cdot \lambda_{s, E 1} \\
Q_{\text {Sensible }, E 1}=\dot{m}_{f, E 1} \cdot C_{p, E 1} \cdot \Delta T_{E 1} \\
Q_{\text {Latent }, E 1}=Q_{\text {Total }, E 1}-Q_{\text {Sensible }, E 1} \\
\dot{m}_{v, E 1}=Q_{\text {Latent }, E 1} / \lambda_{v, E 1} \\
\dot{m}_{v, E 1}=\dot{m}_{d, E 1} \\
\dot{m}_{b, E 1}=\dot{m}_{f, E 1}-\dot{m}_{d, E 1}
\end{gathered}
$$

where $\mathrm{Q}_{\mathrm{Total}, \mathrm{E} 1}=$ total heat in Effect 1 [W],

$\mathrm{Q}_{\text {Sensible,E1 }}=$ sensible heat in Effect 1 [W],

$\mathrm{Q}_{\text {Latent,E1 }}=$ latent heat in Effect 1 [W],

$\dot{\mathrm{m}}_{\mathrm{s}, \mathrm{E} 1}=$ mass flowrate of steam in Effect $1[\mathrm{~kg} / \mathrm{hr}]$,

$\dot{\mathrm{m}}_{\mathrm{f}, \mathrm{E} 1}=$ mass flowrate of feed water in Effect $1[\mathrm{~kg} / \mathrm{hr}]$,

$\dot{\mathrm{m}}_{\mathrm{v}, \mathrm{E} 1}=$ mass flowrate of vapor in Effect $1[\mathrm{~kg} / \mathrm{hr}]$,

$\dot{\mathrm{m}}_{\mathrm{d}, \mathrm{E} 1}=$ mass flowrate of distillate in Effect $1[\mathrm{~kg} / \mathrm{hr}]$,

$\dot{\mathrm{m}}_{\mathrm{b}, \mathrm{E} 1}=$ mass flowrate of brine in Effect $1[\mathrm{~kg} / \mathrm{hr}]$, 
$\lambda_{\mathrm{s}, \mathrm{E} 1}=$ latent heat of steam in Effect $1[\mathrm{~kJ} / \mathrm{kg}]$,

$\lambda_{\mathrm{v}, \mathrm{E} 1}=$ latent heat of vapor produced in Effect $1[\mathrm{~kJ} / \mathrm{kg}]$,

$\mathrm{C}_{\mathrm{p}, \mathrm{E} 1}=$ Specific heat capacity at constant pressure in Effect $1\left[\mathrm{~kJ} / \mathrm{kg} /{ }^{\circ} \mathrm{C}\right]$

$\Delta \mathrm{T}=$ temperature difference between steam and vapor temperature in Effect $1[\mathrm{~K}]$.

Based on these physical data, the overall heat transfer coefficient (U) and the fouling factor (FF) for the evaporator tubes are calculated for monitoring scale formation according to the following equations:

$$
\begin{gathered}
\mathrm{U}=Q /(A \cdot \Delta T) \\
\mathrm{FF}=1 / U_{f}-1 / U_{c}
\end{gathered}
$$

where $\mathrm{Q}=$ heat transferred through the heat transfer surfaces [W],

$\mathrm{A}=$ surface area of the tubes in the effects [m2],

$\Delta \mathrm{T}=$ temperature difference between steam and vapor temperature in Effect $4[\mathrm{~K}]$,

$\mathrm{U}_{\mathrm{f}}=$ overall heat transfer coefficient at any given time $\left[\mathrm{W} /\left(\mathrm{m}^{2} \cdot \mathrm{K}\right)\right]$,

$\mathrm{U}_{\mathrm{c}}=$ overall heat transfer coefficients under clean tube conditions $\left[\mathrm{W} /\left(\mathrm{m}^{2} \cdot \mathrm{K}\right)\right]$.

\subsection{Visual Inspection and Scale Composition Analysis}

As a validation for the $\mathrm{U}$ and $\mathrm{FF}$ calculated from operation data, visual inspection of the tube surface was carried out at the beginning and the end of the 5-month test operation to evaluate the type and degree of scale formed on the tube surface. Also, tube surfaces were flushed with water to check whether the scale is easily removable or not.

During visual inspection, scale samples were collected from the tube surfaces of the first effect which was operated under the most severe operation condition (i.e., TBT of $85^{\circ} \mathrm{C}$ ). The samples were analyzed in the laboratory for the identification and quantification of the chemical composition by the following methods: 1) $\mathrm{Na}^{+}, \mathrm{Ca}^{2+}, \mathrm{Mg}^{2+}$, and $\mathrm{K}^{+}$are analyzed by Inductively Coupled Plasma-Optical Emission Spectrometry (ICP-OES) digesting the sample by a microwave based on USEPA 6010D method [15]; 2) $\mathrm{CO}_{3}{ }^{2-}$, $\mathrm{Cl}^{-}$, and $\mathrm{SO}_{4}{ }^{2-}$ are analyzed according to $\mathrm{BS} 1377-3(1990)$ method [16]: For carbonate, the specimen is treated with a known quantity of acid to finality. The amount of excess acid is determined by titration against sodium hydroxide; for chloride, nitric acid extraction followed by Volhard titrimetric analysis was carried out to quantify chloride; similarly, hydrochloric acid extraction followed by gravimetric analysis was performed for sulfate quantification.

\section{Results and Discussions}

In this study, after operating the pilot plant for 5 months, the following analysis was performed: (1) fouling factor analysis, (2) visual inspection and scale composition analysis, and (3) techno-economic analysis.

\subsection{Fouling Factor}

Thermal performance evaluation was performed during the operation of the pilot plant after excluding data from the first 260 hours from the beginning which is required for the stabilization of the system. During the five months operation, there were two temporary shutdowns (around 700 and 850 hours from the starting time) due to the unexpected failure of power supply. Figure 3 shows the good agreement between the calculated distillate flowrate using heat and mass balance equations, and the measured total distillate with a low root mean square error (RMSE) of 0.079. The results indicates that the calculation of heat and mass balance described in the section 2.2 are reliable to analyzing the system.

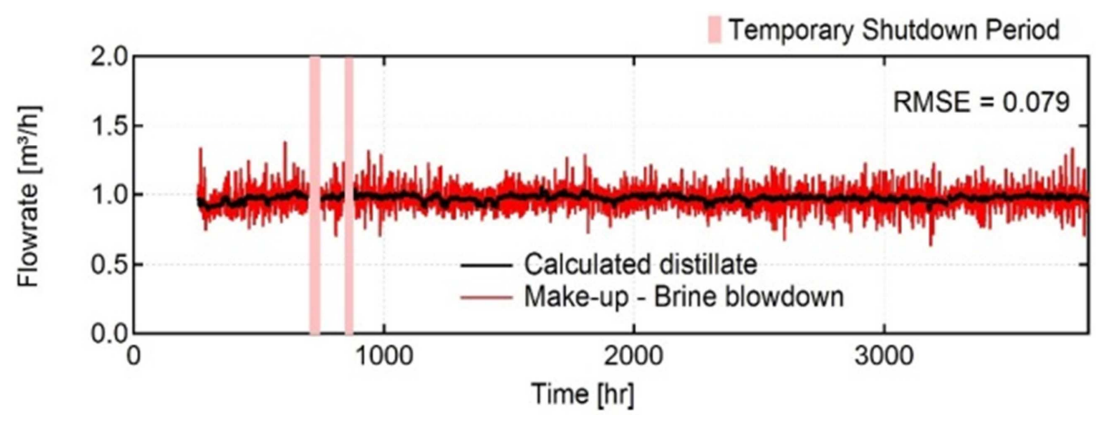

Figure 3. Distillate production.

Figure 4(a) describes temperature profiles of TBT, feed, and make-up seawater for 3,600 hours, which exhibited a stable operation of the pilot plant. Throughout the test period, the TBT was well maintained at $85^{\circ} \mathrm{C}$ as a target condition while the feed temperature was maintained stable at $77^{\circ} \mathrm{C}$ regardless of a slight decrease in the make-up seawater temperature due to seasonal variation. This is because the combined brine flow rate which has been recirculated as the feed water is almost 10 times higher than the make-up seawater flow rate. Figure 4(b) shows temperature profiles of steam and vapor in each effect. The mean temperature differences (MTD) were maintained close to $2{ }^{\circ} \mathrm{C}$ between the vapor temperature of the former effect and that of the latter effect. The difference between the shell side vapor temperature in Effect 1 which is around $84^{\circ} \mathrm{C}$ and the TBT (around $85^{\circ} \mathrm{C}$ ) is approximately corresponding with the boiling point elevation of the concentrated falling film. The MTD (around $4^{\circ} \mathrm{C}$ ) between the steam temperature and the vapor temperature in Effect 1 was relatively higher compared to MTDs 
in other effects. This is presumed to be influenced by the initial physical design of the pilot plant itself. Specially, the steam temperature profile at the inlet of Effect 1 showed slightly increasing trend from around $87^{\circ} \mathrm{C}$ at the beginning after stabilizing to around $88^{\circ} \mathrm{C}$ at the end. This indicates that the tube surfaces were gradually fouled over the period of operation. Accordingly, the motive stream flow rate (depicted in red color in Figure 4(c)) slightly increased from 0.25 to $0.28 \mathrm{~m}^{3} / \mathrm{h}$ (depicted on the secondary y-axis) in response to an increase in fouling. All feed flow rates of each effect are almost maintained as around $8.8 \mathrm{~m}^{3} / \mathrm{h}$ except for the last period from 3,400 to 3,600 hours, which shows some disturbance due to the adjustments and sensitivity of the manual valve in the feed line of each effect. The distillate flow rate was around $1.0 \mathrm{~m}^{3} / \mathrm{h}$ (vertical axis on the right hand side) which is the design flowrate (see the sky-blue color in Figure 4(c)). In Figure 4(d), TDS concentrations in both feed and brine were initially maintained at around 65,000 ppm and 63,000 ppm, respectively, until around 2,000 hours of operation. However, these gradually decreased to $63,000 \mathrm{ppm}$ and $61,000 \mathrm{ppm}$, respectively. It was caused by the decrease in the TDS concentration of make-up seawater due to seasonal variation. And the distillate TDS concentration (see the sky-blue color in Figure 4(d)) was measured mostly below 5 ppm (see vertical axis on the right hand side).
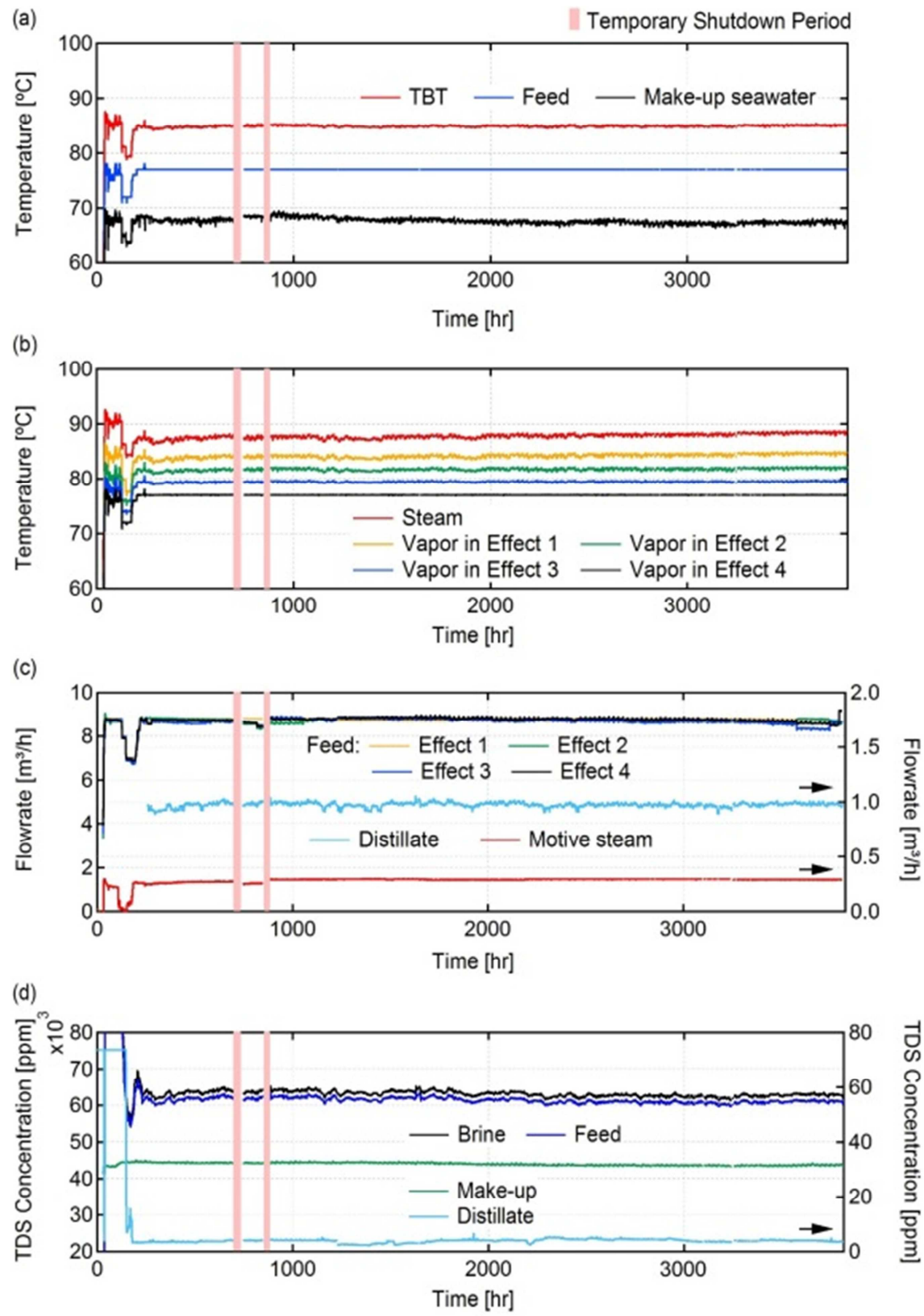

Figure 4. Operational variables of the pilot testing.

Based on the obtained operation data, the normalized PR was calculated by Eq. 1. In Figure 5(a), the normalized PR showed a gradual decreasing trend, because the motive steam flowrate was increased while the distillate flowrate was kept at around $1.0 \mathrm{~m}^{3} / \mathrm{h}$. Also, in Fig 5(b) and 5(c), the normalized overall heat transfer coefficient (U) and the normalized 
fouling factor (FF) were calculated using equations 8 and 9 , respectively. In Figure 5(b), the normalized $U$ value has a slight decreasing trend from 1 to 0.9 with respect to operating time. This trend matches well with the increasing trend of the motive stream flow rate. The decreasing $U$ trend indicates scale deposition on the tube. Also, the normalized FF exhibited a slight increase in value and it was less than the normalized design value of 1.0 during the operating period (see Figure 5(b)). When the FF value reaches the design value during the operation, acid cleaning should be

(a)

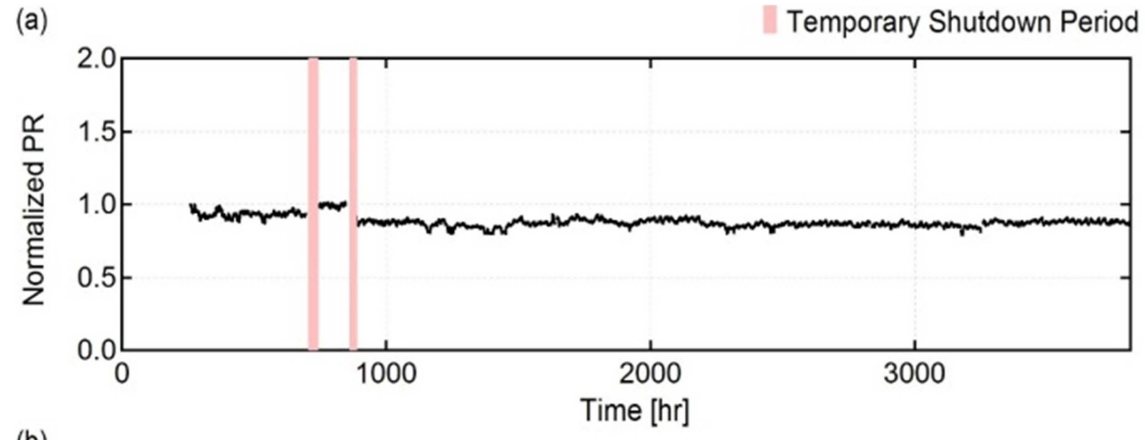

(b)

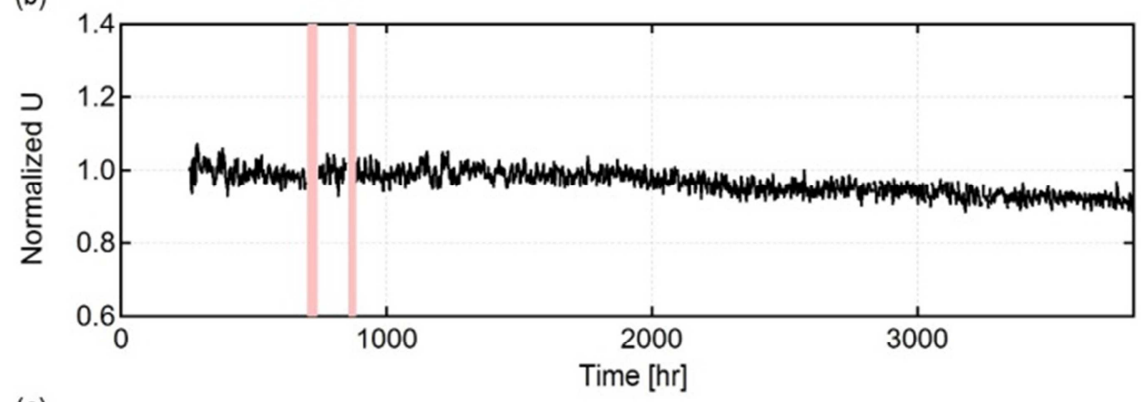

(c)

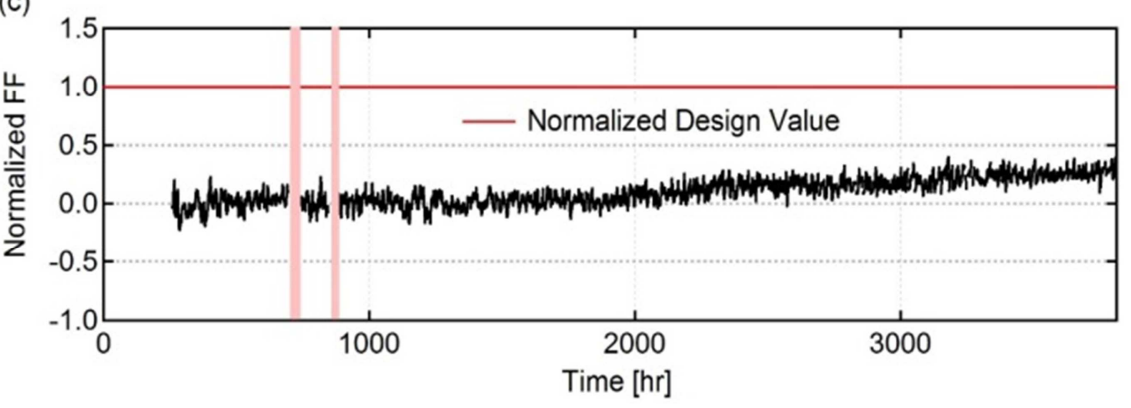

Figure 5. Performance ratio (PR), Overall heat transfer coefficient during the test.

\subsection{Visual Inspection and Scale Composition}

The physical condition of the tube surfaces was investigated to determine whether scale was formed on the tube surfaces through visual inspection after the completion of the 5 month test. Figure 6(a) and 6(b) show the condition of the tube bundle in the first effect before and after the 5 month test, respectively. As shown in the Figure 6(a), tube surfaces have been completely cleaned by acid cleaning before beginning the test. After the 5-month test, a thin film of soft scale was observed on all the tube surfaces (see Figure 6(b)), which aligns with the gradual increase of fouling factor as monitored by operation data. The scale was easily removed by flushing the tube surface with water, which indicates that it was not a hard scale but a soft scale (Figure 6(c)). performed after shutting the plant down for removing scale on the tube surfaces. When the FF value was linearly extrapolated, it is estimated that it intersects the design value of FF after 2.15 years. Although the period of acid cleaning will be different depending on site specific conditions, it is normally done every six months in actual MED-TVC plants. This indicates that the MED-TVC pilot plant has been well operated at a TBT of $85^{\circ} \mathrm{C}$ without scale issues in this 5month demonstration.

Temporary Shutdown Period

After the 5-month test, the chemical analysis of scale composition was carried out to identify whether the scale was soft scale or hard scale. As shown in Table 1, the major anion in the scale was $\mathrm{CO}_{3}{ }^{2-}\left(32.1\right.$ weight \%) rather than $\mathrm{SO}_{4}{ }^{2-}(5.37$ weight $\%$ ), which enables us to conclude that the scale was mostly composed of $\mathrm{CaCO}_{3}$ and $\mathrm{Mg}(\mathrm{OH})_{2}$. This supports the results from visual inspection and thermal calculation of $\mathrm{FF}$, indicating reliable operation of the unit at a TBT of $85^{\circ} \mathrm{C}$. Since the scale was confirmed as a soft scale, it is expected that acid cleaning will be enough to remove the scale without the need for mechanical cleaning as would be required to remove hard scale. 
(a)

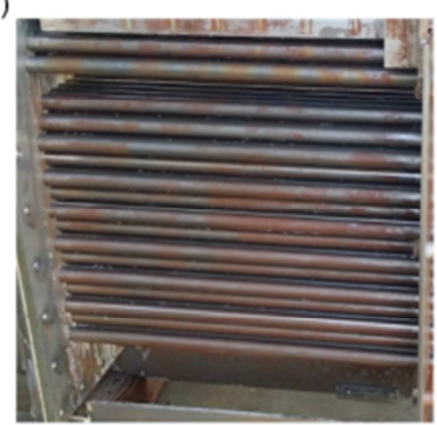

(b)

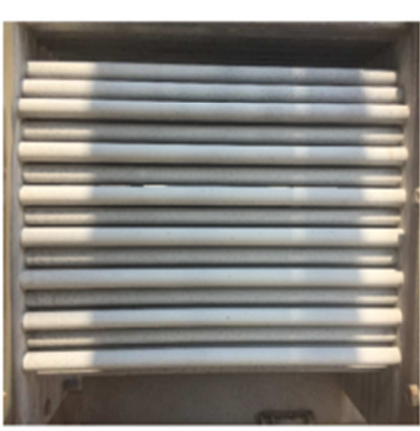

(c)

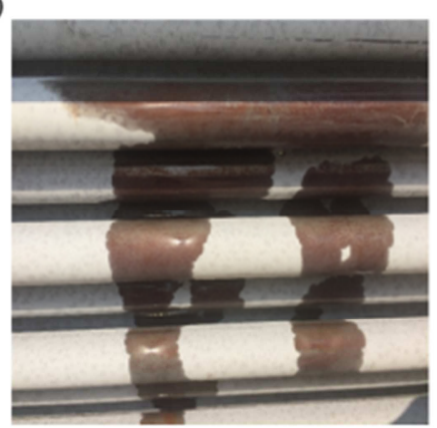

Figure 6. Tube surface conditions.

Table 1. Chemical analysis of the scale composition in first effect.

\begin{tabular}{ll}
\hline Ion & Weight \% \\
\hline $\mathrm{Na}^{+}$ & 7.9 \\
$\mathrm{Ca}^{2+}$ & 4.8 \\
$\mathrm{Mg}^{2+}$ & 7.2 \\
$\mathrm{~K}^{+}$ & 12.68 \\
$\mathrm{CO}_{3}{ }^{2-}$ & 32.1 \\
$\mathrm{Cl}^{-}$ & 9.6 \\
$\mathrm{SO}_{4}{ }^{2-}$ & 5.37 \\
\hline
\end{tabular}

\subsection{Techno-Economic Analysis}

An economic analysis was performed to compare the levelized cost of water (LCOW) of a MED-TVC operating at a TBT of $85^{\circ} \mathrm{C}$ with a brine recirculation cross tube multi stage flashing system (BR-CT MSF) and a conventional MED-TVC operating at $65^{\circ} \mathrm{C}$. The LCOW incuding both CAPEX (i.e., material, civil, erection cost, and transportation cost) and OPEX (i.e., steam, power, chemical, O\&M cost) for each plant have been calculated based on a capacity of 50 million imperior gallon per day (MIGD). Furthermore, the water cost has been based on an oil price of $24 \mathrm{USD} /$ barrel, 30 years plant life time, a discount rate of $5 \%$, and electricity cost of $0.026 \mathrm{USD} / \mathrm{kWh}$. The thermo-physical properties (i.e., mass, temperature, salinity, and enthalpy) of all process streams (i.e., steam and seawater) were determined as a function of temperature, pressure, and salinity based on heat and mass balance equation of each process at the given fixed conditions (i.e., feed condition, capacity, TBT, and so on). As a result, based on the techno-economic evaluation shown in Figure 7 , the TBT $85^{\circ} \mathrm{C}$ MED-TVC plant shows $27 \%$ lower LCOW compared to BR-CT MSF. Furthermore, compared with a conventional TBT $65^{\circ} \mathrm{C}$ MED-TVC unit, its steam consumption can be considerably reduced up to $34 \%$, leading to up to $16 \%$ reduction in the view of LCOW. Therefore, it can be suggested that TBT $85^{\circ} \mathrm{C}$ MED-TVC is a financially competitive and technologically reliable option in the Gulf area which has challenging seawater characteristics.

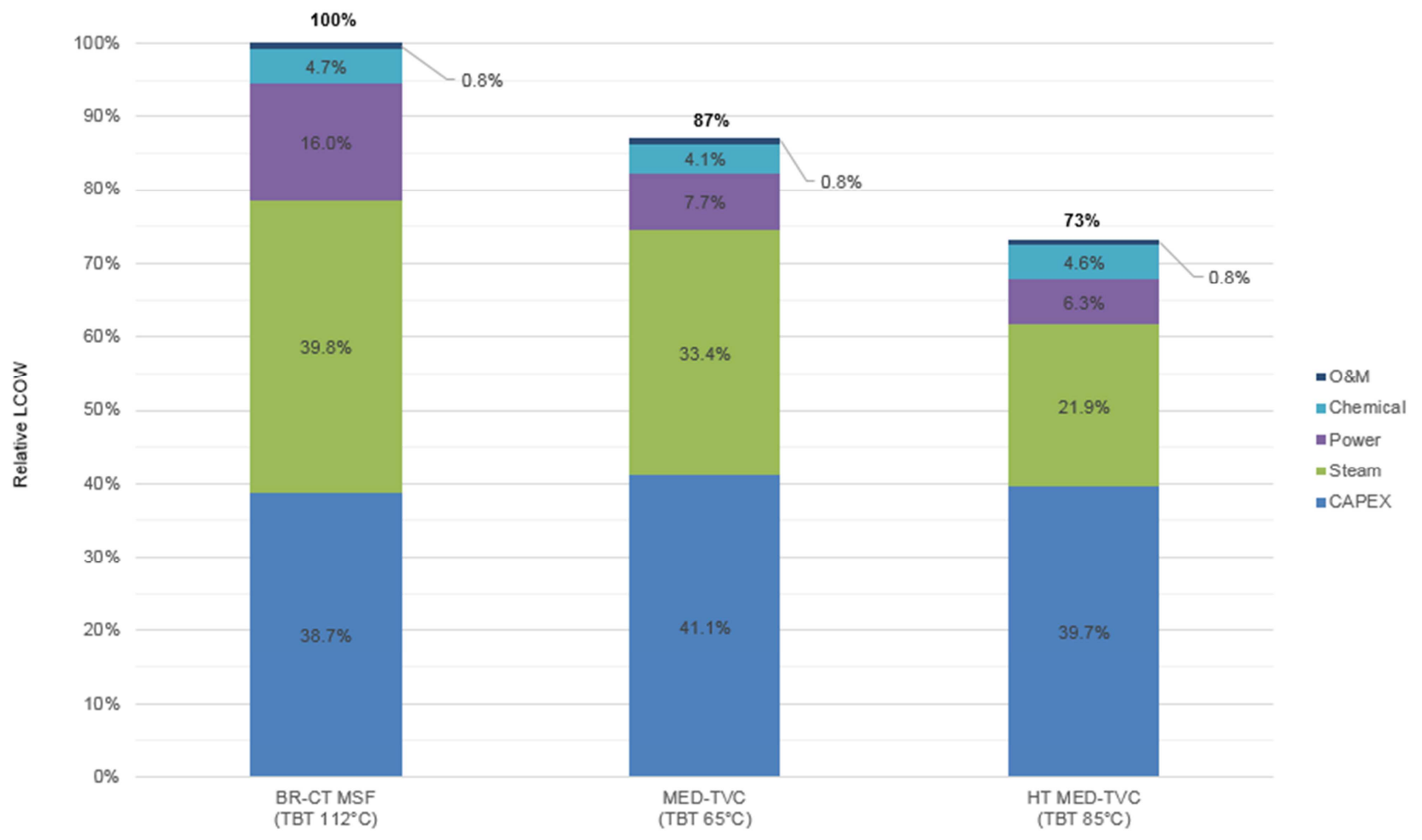

Figure 7. Techno-economic evaluation. 


\section{Conclusions}

In this study, the advanced high TBT MED-TVC was discussed based on experimental results. The following conclusions can be made:

Extensive and rigorous tests which were conducted in a MED pilot plant for a five month period confirmed that it is possible to operate the plant at a top brine temperature (TBT) of $85^{\circ} \mathrm{C}$ safely without scale formation. Currently all operating commercial MED TVC plants are operating at TBT of $65^{\circ} \mathrm{C}$. Techno-economic study revealed that operating the MED TVC at TBT $85^{\circ} \mathrm{C}$ rather than $65^{\circ} \mathrm{C}$ shall reduce steam consumption by more than $34 \%$, and consequently the levelized cost of water shall be reduced by $16 \%$.

\section{References}

[1] S. Lee, J. Cho, and M. Elimelech, Influence of colloidal fouling and feed water recovery on salt rejection of RO and NF membranes, Desalination 160 (2004) 1-12.

[2] M. Barger and R. P. Carnaban, Fouling prediction in reverse osmosis processes, Desalination, 83 (1991) 3-33.

[3] S. Jamaly, N. N. Darwish, I. Ahmed, S. W. Hasan, A short review on reverse osmosis pretreatment technologies, Desalination 354 (2014), 30-38

[4] A. M. Mahmoud, Y. Kim, R. B. Mansour, A. Aithan, Y. Lee, S. Ahmed, H. Varshney, H. Chung, K. Bamardouf, O. Hamed, A. Ghamdi, F. Derman, Experimental analysis and technoeconomic study of once through long tube, Desalination and Water Treatment 73 (2017) 137-144.

[5] I. S. Al-Mutaz, Features of multi-effect evaporation desalination plants, Desalination and Water Treatment 54 (2015) $1-9$.

[6] I. S. Al-Mutaz, I. Wazeer, Current status and future directions of MED-TVC desalination technology, Desalination and Water Treatment 55 (2015) 1-9.
[7] I. S. Al-Mutaz, I. Wazeer, Comparative performance evaluation of conventional multi-effect evaporation desalination processes, Applied Thermal Engineering 73(1) (2014) 1194-1203.

[8] K. A. Khalid, M. A. Antar, A. Khalifa, O. A. Hamed, Allocation of thermal vapour compressor in multi effect desalination systems with different feed configurations, Desalination 426 (2018) 164-173.

[9] C. Sommariva, Desalination Management and Economics, Faversham House Group (2004) Page. 84

[10] N. M. Al-Najem, M. A. Darwish, F. A. Youssef, Thermovapor compression desalters: energy and availability - Analysis of single- and multi-effect systems, Desalination 110 (1997) 223238.

[11] S. Ihm, O. Y. Al-Najdi, O. A. Hamed, G. Jun, H. Chung, Energy cost comparison between MSF, MED and SWRO: Case studies for dual purpose plants, Desalination, 397 (2016) 116-125.

[12] M. A. Saroosh, S. Ahmed, O. A. Hamed, K. A. Al-Shail, S. Ihm, H. Chung, A. S. Al-Ghamdi, F. A. Abu-Derman, Technoeconomic evaluation of concentrated solar thermal (heat only) assisted satellite MED-TVC, IDA World Congress (2015), San Diego, USA.

[13] K. Bourouni, S. Ihm, F. Rezazadeh, A. Nafey, J. K. Park, Analysis of scale in high temperature MED distillers, IDA World Congress (2011), Perth, Western Australia.

[14] S. Ihm, K. Bourouni, C. Siklawi, M. A. Saroosh, A. Nafey, J. Choi and J. Park, Optimization of large-scale high temperature MED-TVC systems: Numerical \& experimental verification, IWA World Water Congress \& Exhibition (2013), Busan, Korea.

[15] U. S. EPA, Method 6010D (SW-846): Inductively coupled plasma-atomic emission spectrometry, Revision 4 (2014). Washington DC, USA.

[16] British Standards Institution, BS 1377: Methods of test for soils for civil engineering purposes - Part 3: Chemical and electro-chemical tests (1990), London, UK. 